\title{
Predicting who will benefit from an Expert Patients Programme self-management course
}

\author{
David Reeves, Anne Kennedy, Catherine Fullwood, Peter Bower, Caroline Gardner, \\ Claire Gately, Victoria Lee, Gerry Richardson and Anne Rogers
}

\begin{abstract}
Background

In England, the Expert Patients Programme, a lay-led chronic disease self-management course, was developed to improve self-care support and skills. The course is designed for anyone with a self-defined longterm condition, and attracts a heterogeneous group of patients. A randomised controlled trial has demonstrated effectiveness in improving subjective health. However, it is not known whether particular patient characteristics predict the impact of the course. Aim

To determine whether baseline characteristics predict clinical outcomes from attendance at a chronic disease self-management course; and to assess whether identification of such characteristics assists in targeting the course to individuals most likely to benefit.

Design of study

A post-hoc subgroup analysis of data from a randomised controlled trial to explore predictors of three trial outcomes: self-efficacy, energy, and healthrelated quality of life.

Setting

Participants with self-defined long-term conditions $(n=629)$ were recruited from community settings in all 28 strategic health authorities in England.

Method

Multiple regression was used to examine interactions between baseline variables and trial outcomes.

Results

The predictors demonstrating significant interactions were: age and general health, and baseline values for self-efficacy, energy levels, and health-related quality of life.

\section{Conclusion}

Participants with lower self-efficacy and health-related quality of life at baseline demonstrated more positive health outcomes. The Expert Patients Programme may have a protective effect on health-related quality of life for patients with poor health and low confidence. Younger people benefited substantially more than older people. Results suggest that positive outcomes associated with the course will be demonstrated with a wide variety of patients, although it may be worthwhile encouraging attendance of younger patients, those lacking confidence, and those coping poorly with their condition.

Keywords

chronic disease; outcome studies; randomised controlled trial; self-care.
\end{abstract}

\section{INTRODUCTION}

Recent government policy advocates self-care support to improve health for people with long-term conditions. ${ }^{1}$ Chronic disease self-management courses are one approach to self-care support. In the English NHS, the Expert Patients Programme has piloted a course open to anyone with a self-defined long-term condition. ${ }^{2}$ The Expert Patients Programme course was modelled on the Chronic Disease SelfManagement Program, developed at Stanford University, ${ }^{3}$ which was based on four conditions (arthritis, heart disease, lung disease, or stroke).,34 Further trials of the course have recruited patients with a self-defined long-term condition, ${ }^{5}$ adapted the generic programme to specific cultures, ${ }^{6-10}$ and tested condition-specific adaptations. ${ }^{11-13}$

A recently completed randomised controlled trial of the Expert Patients Programme showed it was effective in improving subjective measures of health, including a medium effect on self-efficacy (confidence in managing the effects of long-term conditions; effect size $=0.4$ ), and small effects on energy (effect size $=0.2$ ) and health-related quality of life (providing the equivalent of one extra week of

$D$ Reeves, $B S c, P h D$, research fellow (statistics); A Kennedy, $B S c, P h D, S R N$, research fellow; C Fullwood, research associate, MStat, PhD; P Bower, BSc, PhD, reader; C Gardner, $B S c$, research interviewer; $C$ Gately, $B S C, M S c$, research associate; V Lee, BSc, PhD, research associate; $\boldsymbol{A}$ Rogers, $B A$, $M S c, P h D, S R N$, professor, University of Manchester, National Primary Care Research and Development Centre, Manchester. G Richardson, BSc, MSc, research fellow, University of York, Centre for Health Economics, Heslington, York.

Address for correspondence Anne Kennedy, NPCRDC, 5th Floor, Williamson Building, The University of Manchester, Oxford Road, Manchester M13 9PL. E-mail: anne.p.kennedy@manchester.ac.uk

Submitted: 30 May 2007; Editor's response: 2 August 2007; final acceptance: 17 December 2007.

(OBritish Journal of General Practice 2008; 58: 198-203.

DOI: 10.3399/bjgp08X277320 
perfect health per year). ${ }^{5}$ These findings accorded with previous trials of the Stanford course. ${ }^{3}$

The Expert Patients Programme trial had wide inclusion criteria to reflect the broader programme's philosophy of social inclusion: trial patients varied in demographic and health-related characteristics. Therefore, identifying groups of patients for whom the self-management course is most effective is an area for further research.

Secondary analyses to identify such subgroups have so far shown varied results. The initial trial of the self-management course found that outcomes did not vary between different conditions (arthritis, heart disease, stroke, and comorbid conditions). ${ }^{3} \mathrm{~A}$ secondary analysis of a culturally-adapted course also found no difference in effect by condition or sex. ${ }^{7}$ One study found indications that responses to the course varied according to cultural group (Vietnamese, Chinese, Italian, and Greek), with Vietnamese participants showing most change and Italians the least. ${ }^{9}$

Given the highly varied patient population that enters the Expert Patients Programme, a secondary analysis to identify patient characteristics associated with outcomes is potentially useful in helping NHS clinicians and service commissioners to target patients who are most likely to benefit. A previous study used analytic techniques to identify determinants of benefit, with the aim of developing screening tools to maximise the impact and costeffectiveness of interventions. ${ }^{14}$

\section{METHOD}

\section{Patients and intervention}

The Expert Patients Programme is a group intervention (with 8-12 participants) which is led by trained lay people with experience of long-term conditions. It is designed to help participants to develop appropriate self-care skills. The intervention is an adapted and anglicised version of the Stanford Chronic Disease Self-Management Program. ${ }^{3}$ The course involves six 2.5-hour group sessions held weekly in non-NHS premises. The intervention is conducted according to a written manual, and includes sessions on relaxation, diet, exercise, fatigue, breaking the 'symptom cycle', managing pain and medication, and communication.

The trial was designed to reflect the broader Expert Patients Programme, and no specific inclusion or exclusion criteria were used beyond a self-defined long-term condition. Recruitment was carried out at community settings in all 28 strategic health authorities in England.

\section{Trial design}

The trial methods and results have been reported in

\section{How this fits in}

There is increasing evidence of the effectiveness of chronic disease self-

management courses. Recent research has found they may have a small-tomoderate effect in improving people's subjective health. However, there is a lack of knowledge about the characteristics of patients who might benefit most from such an approach. This research addresses this and shows that younger patients and those who lack confidence and cope poorly with their condition may gain the most from attending an Expert Patients Programme.

detail elsewhere. ${ }^{5}$ In summary, the design was a twoarm pragmatic randomised controlled trial with a waiting-list control group. A total of 629 patients were recruited between April 2003 and April 2005. Followup was at 6 months after baseline.

\section{Measures}

Outcomes examined in the present analysis were restricted to a priori primary outcomes for which the Expert Patients Programme was found to have a significant effect:

- Self-efficacy ${ }^{15}$ - the self-efficacy scale contained 19 items related to confidence in: achieving exercise participation (three items), and managing disease (five items), symptoms (five items), and depression (six items). Each item was scored on a 10 -point scale ranging from 'not at all confident' to 'very confident'. The final score was the mean of the four subscales expressed out of 100 .

- Energy ${ }^{15}$ - the energy scale had five items (for example, 'Did you feel worn out?', 'Did you have enough energy?') scored on a six-point scale ranging from 'none of the time' to 'all of the time'. The final score was a sum of the items expressed out of 100 .

- Health-related quality of life - the EQ-5D, which is the EuroQol Group's health status instrument (fivedimensional format), measures patient health status across five dimensions (mobility, self-care, usual activities, pain/discomfort, and anxiety/depression), each with three possible responses (no problem, moderate problems, or severe problems). This allows categorisation of patients according to state of heath, and each state is mapped onto a scale where zero equates to dead and 100 equates to full health, based on interviews with a sample of 3395 members of the UK public. ${ }^{16}$

One other primary trial outcome, health service use (the sum of self-reported GP visits, accident and emergency attendances, and outpatient visits), was not affected by the intervention and does not appear as an outcome in the present analysis. 
Figure 1. Relationship between change in self-efficacy and baseline self-efficacy score, by treatment group (adjusted for patient age, sex, ethnicity, disease condition, general health, and accommodation). Error bars indicate 95\% confidence intervals. $E P P=$ Expert Patients Programme.
Figure 2. Relationship between change in energy and patient age, by treatment group (adjusted for energy score at baseline and patient sex, ethnicity, disease condition, general health, and accommodation). Error bars indicate 95\% confidence intervals. $E P P=$ Expert Patients Programme.

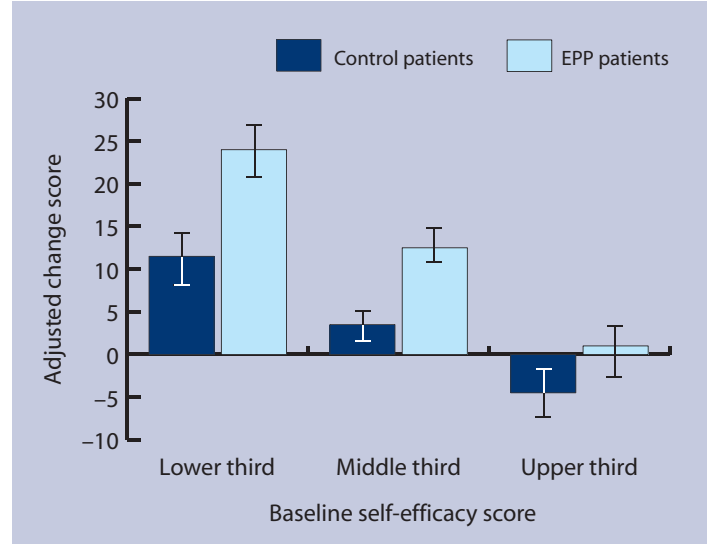

The selected predictors included a range of sociodemographic variables and baseline values of the trial outcomes. Appendix 1 shows that the two groups were well balanced on all predictors at baseline.

\section{Analysis}

Analyses were conducted using multiple regression in Stata (version 9). To test whether a predictor moderated the effect of the course on the outcome variable (self-efficacy, energy, or health-related quality of life), the regression included terms representing the predictor's main effect and its interaction with treatment group. ${ }^{17}$

A separate regression was run for each predictor. Initially, the model consisted of treatment group, baseline value of the outcome, and the stratification used in the original randomisation: age category, sex, condition, general health, accommodation type, and ethnicity.

The predictor was then added as a main effect which was tested by determining if this improved the model (that is, significantly increased the $\mathrm{R}^{2}$ value), before adding and testing its interaction with treatment group.

Courses were clustered within tutor/trainer teams, based in strategic health authorities. Because the number of authorities was large relative to sample

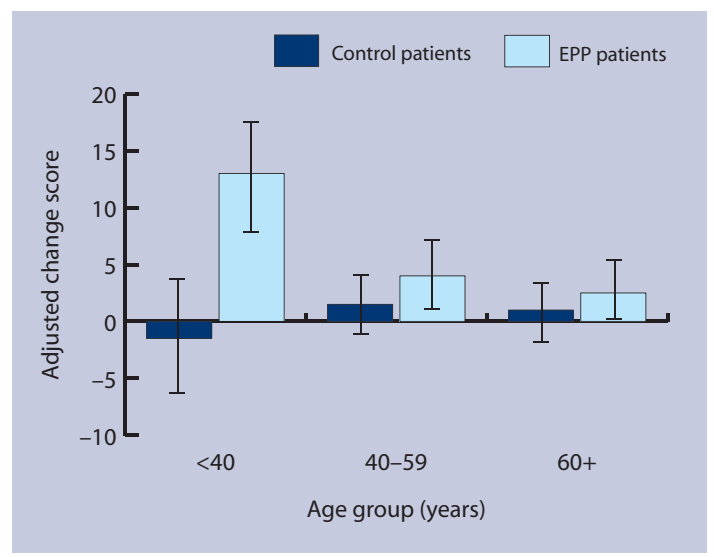

size, the study did not cluster by strategic health authority in the main analysis; ${ }^{5}$ instead, regressions were repeated with an adjustment for strategic health authority in a sensitivity analysis. Findings that were not supported by the sensitivity analysis are indicated in the Appendices 2 and 3. Interactions were tested using an alpha level of $5 \%$.

\section{RESULTS}

$P$-values for the interactions and main effects were summarised (Appendix 2). Main effects measure the impact of a predictor on an outcome regardless of treatment group; these are reported purely for completeness and are not discussed further. Also, interpretation of main effects must be cautious for variables involved in a significant interaction. Six interactions were significant in both the primary and sensitivity analyses, related to age, general health, and baseline values for self-efficacy, energy, and health-related quality of life. To assist in interpreting these interactions, the scores were subdivided on each predictor into three subgroups (as equal in size as the data allowed, with the exceptions of age and general health which were pre-classified), and an effect size was calculated (Cohen's d) for each subgroup (Appendices 2 and 3). In accordance with Cohen, an effect of 0.2 was taken to be small, 0.5 to be moderate, and 0.8 to be large. ${ }^{18}$

\section{Predictors of self-efficacy}

The Expert Patients Programme had a significantly greater impact on the self-efficacy of participants with low self-efficacy scores at baseline $(P=0.006)$, compared with those who began with higher scores (Appendices 2 and 3). The effect on participants in the lower third of scores at baseline was moderate to large (effect size $=0.56 ; 95 \%$ confidence interval $[\mathrm{Cl}]$ $=0.37$ to 0.75 ), but only small for those with scores in the upper third (effect size $=0.22 ; 95 \% \mathrm{Cl}=0.02$ to 0.41 ; Figure 1).

Although there was little or no improvement in selfefficacy for those who scored well initially, possible gains at the high end were restricted by the ceiling on self-efficacy scores (maximum possible score is 100). There is also weak evidence $(P=0.035)$ that the course had a greater impact on the self-efficacy of people who scored poorly in terms of health-related quality of life at baseline (Appendices 2 and 3), even after controlling for baseline self-efficacy scores.

\section{Predictors of energy}

In terms of energy, the Expert Patients Programme had a substantially greater effect on younger participants $(P=0.006)$. Patients under 40 years of age improved their energy score by an average of 13.0 $(95 \% \mathrm{Cl}=8.0$ to 18.0$)$ points, compared with mean 
gains of $4.2(95 \% \mathrm{Cl}=1.2$ to 7.2$)$ points and $2.7(95 \%$ $\mathrm{Cl}=0.1$ to 5.3) points for participants in the older age groups (Figure 2). In all age groups, control patients showed only small changes in mean energy levels.

\section{Predictors of health-related quality of life}

The impact of the Expert Patients Programme on heath-related quality of life was significantly related to baseline levels of general health $(P=0.022)$, selfefficacy $(P=0.007)$, and health-related quality of life $(P=0.013)$. Relative to equivalent control patients, course participants who were initially at the lowest levels on these measures benefited most from the course. Effect sizes were small to moderate (Appendix 3), but the finding may be important for other reasons. Figure 3 shows that, whereas healthrelated quality of life declined in control patients with low-to-moderate levels of self-efficacy, no such decline occurred in intervention patients who, at baseline, had equivalent levels of self-efficacy. A similar result was observed in those with poor general health.

\section{DISCUSSION}

\section{Summary of main findings}

Results suggest that people who have lower selfefficacy and health-related quality of life at baseline gain most from the Expert Patients Programme. Younger people may also benefit substantially more than older people, although no other sociodemographic predictors of benefit from the Expert Patients Programme were identified.

\section{Strengths and limitations of the study}

Participants were volunteers with an interest in attending an Expert Patients Programme; therefore, the results and the subgroup analyses may not generalise to the wider population with long-term conditions.

The randomised controlled trial was not powered to detect predictors of outcome. Low power is sometimes used to argue against interaction tests, but it is also argued that they are of value for that very reason: they inhibit false or premature claims. ${ }^{17}$ In general, only strong interaction effects will reach statistical significance if the trial has low power. To aid interpretation, effect sizes were calculated for subgroups of the sample. The effect size estimates are precise enough (with error bounds of \pm 0.2 or less) to distinguish confidently between small, moderate, and large effects.

The large number of statistical significance tests conducted increased the likelihood that at least one test is significant by chance. ${ }^{19}$ This risk could be reduced by adjusting the $\alpha$ level for significance, for example via the Bonferroni method. ${ }^{20}$ However,

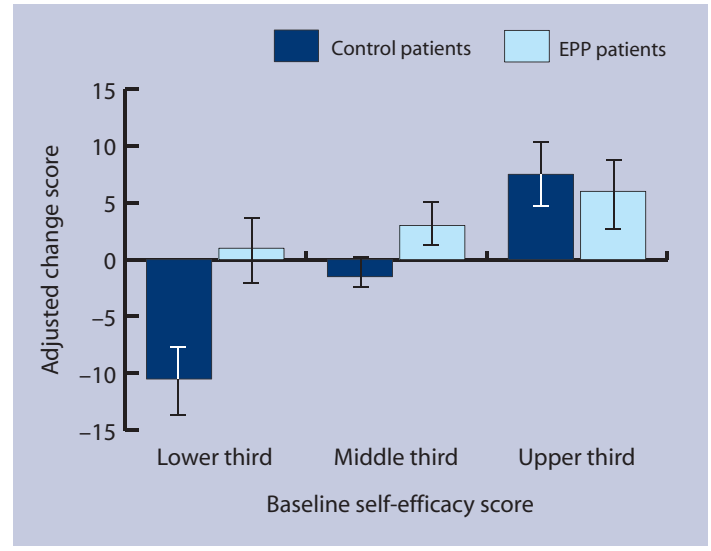

Figure 3. Relationship between change in health-related quality of life and baseline selfefficacy, by treatment group (adjusted for health-related quality of life at baseline and patient age, sex, ethnicity, disease condition, general health, and accommodation). Error bars indicate $95 \%$ confidence intervals. EPP $=$ Expert Patients Programme. protecting the type 1 error rate (the chance of falsely rejecting even a single test) increases the likelihood of type 2 errors (the chance of failing to detect one or more genuine relationships). ${ }^{21}$ The desirable balance between these two kinds of error depends on the application. For the purposes of exploratory analysis and hypothesis generation, it is important that the type 2 rate is not too high, or potentially important relationships may be excluded prematurely. ${ }^{22,23}$ For this reason, the conventional level of significance, $P<0.05$, was used. ${ }^{24}$

Guidelines concerning secondary analyses highlight a number of important methodological considerations other than statistical significance. ${ }^{19}$ Considerations relevant to the current results are: clinical significance of the results; whether the hypothesised predictors of outcome were specified in advance; consistency of the findings with the wider literature; and existence of indirect evidence that supports the hypothesised difference. Caution is necessary in interpreting the current analyses, as a relatively large number of predictor variables were tested, which were not specified in advance. Partly this reflects the lack of a comprehensive theoretical model that would allow such prespecification. The predictors tested were those available in the trial data set. Other unmeasured variables (for example, personality and social support) may be important predictors, but the need to minimise responder burden made more comprehensive assessment inappropriate.

\section{Comparison with existing literature}

The present findings concur with previous analyses showing that patients' underlying conditions do not predict any difference in outcomes.,7 However, analyses of the impact of baseline self-efficacy and health have not been reported previously. It is also suggested that other research teams who have undertaken recent trials of chronic disease selfmanagement courses ${ }^{7,11}$ investigate whether the present results can be replicated. 


\section{Implications for future research and clinical practice}

The current results require validation by other studies, and if that occurs there are several important implications for the delivery of the Expert Patients Programme. This trial included an accompanying process evaluation which illuminated a number of practical implementation issues related to recruitment to the Expert Patients Programme. Recruitment of participants during the pilot phase was problematic, because the programme did not fit well with current delivery of chronic disease-management services in primary, secondary, and social care. Also, professionals were not engaged either in recruitment to courses or incorporating self-care skills training into their work with patients. ${ }^{25}$ It was found that Expert Patients Programme staff concentrated on 'easy' targets for recruitment (for example, patient support groups whose members are likely to appreciate and value self-care skills), to ensure there were enough course participants. ${ }^{26}$ As a result, recruitment tended to be biased towards people who were already good self-managers.

The present analysis suggested that patients with low self-efficacy and poor health gain most from the course, and might encourage service commissioners and healthcare professionals planning courses in chronic disease self-management to concentrate resources on targeting people who lack confidence in their abilities to self-manage, or who are coping badly. However, some caution must be applied, as those with very low self-efficacy and health at baseline may not have entered the trial at all, and may not demonstrate the same degree of improvement as patients in the current study.

Younger people were more likely to benefit from the Expert Patients Programme in terms of energy gain. A patient experience study by the present authors (not yet published) indicated that younger people found the course set up and group discussions unappealing, mainly because the majority of those on courses were older people with different needs or experiences. Possibly, more could be done to make the course more appropriate to the needs of younger participants (for example, increasing the focus on employment-related issues), to ensure that they are satisfied with the course and have improved outcomes.

The present results suggest that the Expert Patients Programme may have a protective effect on health-related quality of life for patients with poor health or low confidence. The course can help such patients to resist a deterioration in their health-related quality of life that would otherwise have occurred. If this is the case, the results have important implications. However, the finding is the outcome of a complex analysis controlled for many co-varying factors, and would need confirmation in other studies.

This study replicates previous findings that the patients' underlying conditions do not predict any difference in outcomes. ${ }^{3,7}$ This result strengthens the argument that self-care support can be provided on a generic basis, which may be easier and more efficient to provide. However, it should be noted that the patient experience study did report some dissatisfaction, among a proportion of patients, with the lack of disease-specific information provided. ${ }^{26}$

In summary, to maximise the impact and benefit of the Expert Patients Programme, more effort could be made to encourage health professionals to refer patients who are likely to be lacking in confidence or ability to self-manage. Changes to the course in order to make it more attractive to younger patients may also be required.

\section{Funding body}

The randomised controlled trial this study is based on was funded by the Department of Health (trial identifier: ISRCTN7053234)

\section{Ethical approval}

Ethics approval for the trial was given by North West MREC (MREC 03/8/3)

\section{Competing interests}

The authors have stated that there are none

\section{Acknowledgements}

The authors would like to thank Fran Morris, Claire Chandler, and Sophie Jerrim for their hard work in the administration of the trial; the patients who kindly agreed to participate and complete the written assessments; the staff within the Expert Patients Programme and the primary care trusts who helped recruit patients; and Ayesha Dost and Geoff Royston at the Strategy Directorate of the Department of Health. NPCRDC is a department of the University of Manchester but is funded by the Department of Health. The views expressed in this paper are the views of the authors and not the funding body.

\section{Discuss this article}

Contribute and read comments about this article on the Discussion Forum: http://www.rcgp.org.uk/bjgp-discuss.

\section{REFERENCES}

1. Department of Health. Our health, our care, our say: a new direction for community services. London: The Stationery Office, 2006.

2. Department of Health. The expert patient: a new approach to chronic disease management in the 21st Century. London: The Stationery Office, 2001.

3. Lorig K, Sobel DS, Stewart AL, et al. Evidence suggesting that a chronic disease self-management program can improve health status while reducing hospitalization a randomized trial. Med Care 1999; 37(1): 5-14.

4. Lorig KR, Ritter P, Stewart AL, et al. Chronic disease selfmanagement program 2-year health status and health care utilization outcomes. Med Care 2001; 39(11): 1217-1223.

5. Kennedy A, Reeves D, Bower P, et al. The effectiveness and cost effectiveness of a national lay-led self care support programme for patients with long-term conditions: a pragmatic randomised controlled trial. J Epidemiol Community Health 2007; 61(3): 254-261.

6. Fu D, Fu H, McGowan P, et al. Implementation and quantitative evaluation of chronic disease self-management programme in Shanghai, China: randomized controlled trial. Bull World Health Organ 2003; 81(3): 174-182.

7. Griffiths C, Motlib J, Azad A, et al. Randomised controlled trial of a lay-led self-management programme for Bangladeshi patients with 
chronic disease. Br J Gen Pract 2005; 55(520): 831-837.

8. Lorig K, Ritter P, Gonzales VM. Hispanic chronic disease selfmanagement - a randomized community-based outcome trial. Nurs Res 2003; 52(6): 361-369.

9. Swerissen H, Belfrage J, Weeks A, et al. A randomised control tria of a self-management program for people with a chronic illness from Vietnamese, Chinese, Italian and Greek backgrounds. Patient Educ Couns 2006; 64(1-3): 360-368.

10. Siu AMH, Chan CCH, Poon PKK, et al. Evaluation of the chronic disease self-management program in a Chinese population. Patient Educ Couns 2007; 65(1): 42-50

11. Buszewicz M, Rait G, Griffin M, et al. Self management of arthritis in primary care: randomised controlled trial. BMJ 2006; 333(7574): 879.

2. Haas M, Groupp E, Muench J, et al. Chronic disease selfmanagement program for low back pain in the elderly. $J$ Manipulative Physiol Ther 2005; 28(4): 228-237.

13. Lorig K, Ritter P, Laurent D, Fries J. Long-term randomized controlled trials of tailored-print and small-group arthritis selfmanagement interventions. Med Care 2004; 42(4): 346-354.

14. Ruel MT, Rivera J, Habicht JP, Martorell R. Differential response to early nutrition supplementation: long-term effects on height at adolescence. Int J Epidemiol 1995; 24(2): 404-412.

15. Lorig K, Stewart AL, Ritter P, et al. Outcome measures for healt education and other health care interventions. Thousand Oaks: Sage Publications, 1996.

16. Kind P. The EuroQol instrument: an index of health-related quality of life. In: Spilker B (ed). Quality of life and pharmacoeconomics in clinical trials. 2nd edn. Philadelphia: Lippincott-Raven, 1996: $191-201$
17. Pocock SJ, Assman SE, Enos LE, Kasten LE. Subgroup analysis, covariate adjustment and baseline comparisons in clinical trial reporting: current practice and problems. Stat Med 2002; 21(19): 2917-2930

18. Cohen J. Statistical power analysis for the behavioral sciences. $2 \mathrm{nd}$ edn. New York: Lawrence Erlbaum, 1998.

19. Freemantle N. Interpreting the results of secondary end points and subgroup analyses in clinical trials: should we lock the crazy aunt in the attic? BMJ 2001; 322(7292): 989-991.

20. Lagakos SW. The challenge of subgroup analysis - reporting without distorting. N Engl J Med 2006; 354(16): 1667-1669.

21. Benjamini Y, Yekutieli D. The control of the false discovery rate in multiple testing under dependency. Ann Stat 2001; 29(4): 1165-1188.

22. Nakegawa S. A farewell to Bonferroni: the problems of low statistical power and publication bias. Behav Ecol 2004; 15(6): 1044-1045.

23. Storey JD, Tibshirani R. Statistical significance for genomewide studies. Proc Natl Acad Sci USA 2003; 100(16): 9440-9445.

24. Moran MD. Arguments for rejecting the sequential Bonferroni in ecological studies. Oikos 2003; 100(2): 403-405.

25. Kennedy A, Rogers A, Gately C. Assessing the introduction of the Expert Patients Programme into the NHS: a realistic evaluation of recruitment to a national lay led self care initiative. Prim Health Care Res Dev 2005; 6(2): 137-148.

26. Kennedy A, Gately C, Rogers A. Process evaluation of the EPP report II: Examination of the implementation of the Expert Patients Programme within the structures and locality contexts of the NHS in England. University of Manchester: National Primary Care Research and Development Centre, 2005. 


\begin{tabular}{|c|c|c|}
\hline Characteristic & $\begin{array}{l}\text { Intervention } \\
(n=313)\end{array}$ & $\begin{array}{l}\text { Control } \\
(n=316)\end{array}$ \\
\hline \multicolumn{3}{|l|}{ Age in years, $n(\%)$} \\
\hline$<40$ & $48(15.3)$ & $51(16.1)$ \\
\hline $40-59$ & $130(41.5)$ & $130(41.1)$ \\
\hline$\geq 60$ & $135(43.1)$ & $135(42.7)$ \\
\hline Female, $n(\%)$ & $219(70.0)$ & $220(69.6)$ \\
\hline Ethnicity: white, $n$ (\%) & $298(95.2)$ & $299(94.6)$ \\
\hline Lives alone, $n(\%)$ & $82(26.2)$ & $93(29.4)$ \\
\hline \multicolumn{3}{|l|}{ Highest educational qualification, ${ }^{a} n(\%)$} \\
\hline None or up to GCSE/O level & $123(39.4)$ & $102(32.4)$ \\
\hline A-level, vocational, or professional & $138(44.2)$ & $160(50.8)$ \\
\hline Degree & $51(16.4)$ & $53(16.8)$ \\
\hline Accommodation: owner-occupied, $n$ (\%) & $214(68.4)$ & $214(67.7)$ \\
\hline \multicolumn{3}{|l|}{ Self-reported main chronic condition, $n$ (\%) } \\
\hline Musculoskeletal & $106(33.9)$ & 107 (33.9) \\
\hline Diabetes & 35 (11.2) & $37(11.7)$ \\
\hline Heart disease & $16(5.1)$ & $18(5.7)$ \\
\hline Other & $156(49.8)$ & $154(48.7)$ \\
\hline $\begin{array}{l}\text { Medically unexplained symptoms (defined as: back pain, myalgic } \\
\text { encephalomyelitis, chronic fatigue, irritable bowel syndrome), } n(\%)\end{array}$ & $59(18.9)$ & $70(22.2)$ \\
\hline \multicolumn{3}{|l|}{ Years spent living with the condition, ${ }^{a} n(\%)$} \\
\hline$<5$ & $82(26.9)$ & $90(29.0)$ \\
\hline $5-9$ & $68(22.3)$ & $71(22.9)$ \\
\hline$\geq 10$ & $155(50.8)$ & $149(48.1)$ \\
\hline $\begin{array}{l}\text { Life satisfaction (satisfaction with work, finances, leisure, friendships, } \\
\text { accommodation, living arrangements, family relationships, and } \\
\text { personal safety), mean (SD) }\end{array}$ & $4.6(0.9)$ & $4.7(0.9)$ \\
\hline $\begin{array}{l}\text { Self-care activities (number of self-reported activities out of: diet, exercise, } \\
\text { complementary approaches, relaxation, and information seeking), mean (SD) }\end{array}$ & $11.0(2.4)$ & $11.2(2.4)$ \\
\hline \multicolumn{3}{|l|}{ Self-reported general health, $n(\%)$} \\
\hline Fair/poor & $191(61.0)$ & $190(60.1)$ \\
\hline Good/very good/excellent & $122(39.0)$ & $126(39.9)$ \\
\hline \multicolumn{3}{|l|}{ Self-reported baseline health characteristics, mean (SD) } \\
\hline Self-efficacy & $45.9(21.5)$ & $47.7(22.3)$ \\
\hline Energy & $32.6(19.5)$ & $33.3(20.1)$ \\
\hline Health-related quality of life & $47.1(33.5)$ & $47.5(33.1)$ \\
\hline Healthcare use & $8.6(7.3)$ & $9.1(8.1)$ \\
\hline $\begin{array}{l}\text { Preference for course (measured on 7-point scale from } \\
\text { 'Start the course now' to 'Wait } 6 \text { months'), mean (SD) }\end{array}$ & $3.2(1.8)$ & $3.4(1.8)$ \\
\hline
\end{tabular}




\section{Appendix 2. Summary of $\boldsymbol{P}$-values for main effects and interactions.}

\begin{tabular}{|c|c|c|c|c|c|c|}
\hline & \multicolumn{2}{|c|}{ Self-efficacy } & \multicolumn{2}{|c|}{ Energy } & \multicolumn{2}{|c|}{ HR-QOL } \\
\hline & Main & Interaction & Main & Interaction & Main & Interaction \\
\hline $\mathrm{Age}^{\mathrm{a}}$ (3 levels) & 0.328 & 0.146 & 0.167 & 0.006 & 0.135 & 0.170 \\
\hline Sexa (2 levels) & 0.271 & 0.915 & 0.834 & 0.623 & 0.628 & 0.449 \\
\hline Ethnicity ${ }^{a}$ (2 levels) & 0.255 & 0.241 & 0.849 & 0.849 & 0.249 & 0.632 \\
\hline Lives alone $^{\text {a }}$ ( 2 levels) & 0.589 & 0.496 & 0.249 & 0.824 & 0.173 & 0.079 \\
\hline Educational level ${ }^{a}$ (3 levels) & 0.842 & 0.074 & 0.856 & 0.341 & 0.244 & 0.930 \\
\hline Accommodation type ${ }^{a}$ (2 levels) & 0.263 & 0.375 & 0.233 & 0.857 & 0.273 & 0.412 \\
\hline Condition $^{\mathrm{a}}$ (4 levels) & 0.246 & 0.162 & 0.390 & 0.971 & 0.108 & 0.364 \\
\hline Medically unexplained ${ }^{a}$ (2 levels) & 0.622 & 0.346 & 0.086 & 0.103 & 0.834 & 0.520 \\
\hline Years with condition ${ }^{\mathrm{a}}(3$ levels) & 0.076 & 0.657 & $0.026^{b}$ & 0.343 & 0.433 & 0.500 \\
\hline Life satisfaction & $<0.001$ & 0.335 & $<0.001$ & 0.733 & 0.008 & 0.190 \\
\hline Self-care & 0.864 & 0.067 & 0.031 & 0.442 & 0.275 & 0.144 \\
\hline General healtha (2 levels) & 0.385 & 0.107 & 0.002 & 0.300 & $<0.001$ & 0.022 \\
\hline Baseline self-efficacy & $<0.001$ & 0.006 & $<0.001$ & 0.399 & $<0.001$ & 0.007 \\
\hline Baseline energy & 0.083 & 0.063 & $<0.001$ & 0.963 & 0.016 & $0.038^{b}$ \\
\hline Baseline HR-QOL & 0.003 & 0.035 & $<0.001$ & 0.285 & $<0.001$ & 0.013 \\
\hline Healthcare use & 0.388 & 0.123 & 0.389 & $0.037 \mathrm{~b}$ & 0.723 & 0.947 \\
\hline Preference for course & 0.949 & 0.229 & 0.912 & 0.419 & 0.593 & 0.284 \\
\hline
\end{tabular}

${ }^{a}$ Categorical variable: unless indicated, variables were treated as continuous. ${ }^{b}$ Not significant when controlled for strategic health authority. HR-QOL = health-related quality of life.

\section{Appendix 3. Subgroup effect sizes ${ }^{a}$ for significant interactions.}

\begin{tabular}{|c|c|c|c|c|}
\hline \multirow{2}{*}{$\frac{\text { Outcome }}{\text { Self-efficacy }}$} & \multirow{2}{*}{$\begin{array}{c}\text { Interacting factor } \\
\text { Self-efficacy }\end{array}$} & \multicolumn{3}{|c|}{ Subgroup effect size, Cohen's d (95\% Cl) } \\
\hline & & Lower third & Middle third & Upper third \\
\hline & & $0.56(0.37$ to 0.75$)$ & $0.42(0.30$ to 0.54$)$ & 0.22 (0.02 to 0.41$)$ \\
\hline Self-efficacy & HR-QOL & $0.57(0.36$ to 0.79$)$ & $0.36(0.24$ to 0.49$)$ & $0.29(0.13$ to 0.46$)$ \\
\hline Energy & Age group & $\begin{array}{c}<40 \text { years } \\
0.73(0.37 \text { to } 1.09)\end{array}$ & $\begin{array}{c}40-59 \text { years } \\
0.13(-0.07 \text { to } 0.33)\end{array}$ & $\begin{array}{c}\geq 60 \text { years } \\
0.10(-0.09 \text { to } 0.28)\end{array}$ \\
\hline Energy & Healthcare use ${ }^{b}$ & $\begin{array}{c}0-2 \text { visits } \\
0.06(-0.12 \text { to } 0.24)\end{array}$ & $\begin{array}{c}3-5 \text { visits } \\
0.14(0.0 \text { to } 0.27)\end{array}$ & $\begin{array}{c}6 \text { visits or more } \\
0.31(0.14 \text { to } 0.48)\end{array}$ \\
\hline HR-QOL & General health & $\begin{array}{c}\text { Poor to fair } \\
0.25(0.09 \text { to } 0.41)\end{array}$ & $\begin{array}{l}\text { Good to excellent } \\
-0.05(-0.24 \text { to } 0.15)\end{array}$ & \\
\hline HR-QOL & Self-efficacy & $\begin{array}{c}\text { Lower third } \\
0.34(0.14 \text { to } 0.54)\end{array}$ & $\begin{array}{c}\text { Middle third } \\
0.14(0.02 \text { to } 0.26)\end{array}$ & $\begin{array}{c}\text { Upper third } \\
-0.05(-0.25 \text { to } 0.15)\end{array}$ \\
\hline HR-QOL & Energy $^{b}$ & 0.28 (0.09 to 0.48$)$ & 0.17 (0.04 to 0.29$)$ & $-0.01(-0.21$ to 0.19$)$ \\
\hline HR-QOL & HR-QOL & 0.35 (0.13 to 0.56$)$ & $0.09(-0.03$ to 0.22$)$ & $-0.03(-0.20$ to 0.14$)$ \\
\hline
\end{tabular}

${ }^{a}$ Effect sizes after adjustment for baseline values of the following (except those that were also the interacting factor): outcome, patient age, sex, ethnicity, disease condition, general health, and accommodation. ${ }^{\mathrm{b}}$ Not significant when controlled for Strategic Health Authority. HR-QOL = health-related quality of life. 